University of South Florida

DIGITAL COMMONS

Digital Commons @ University of

@ UNIVERSITY OF SOUTH FLORIDA

South Florida

2012

\title{
Using GIS to enhance programs serving emancipated youth leaving foster care
}

\author{
Catherine Batsche \\ University of South Florida, cbatsche@usf.edu \\ Steven Reader \\ University of South Florida, sreader@usf.edu
}

Follow this and additional works at: https://digitalcommons.usf.edu/dean_cbcs

Part of the Social and Behavioral Sciences Commons

\section{Scholar Commons Citation}

Batsche, Catherine and Reader, Steven, "Using GIS to enhance programs serving emancipated youth leaving foster care" (2012). Dean's Office Publications. 15.

https://digitalcommons.usf.edu/dean_cbcs/15

This Article is brought to you for free and open access by the College of Behavioral and Community Sciences at Digital Commons @ University of South Florida. It has been accepted for inclusion in Dean's Office Publications by an authorized administrator of Digital Commons @ University of South Florida. For more information, please contact digitalcommons@usf.edu. 
Provided for non-commercial research and education use. Not for reproduction, distribution or commercial use.

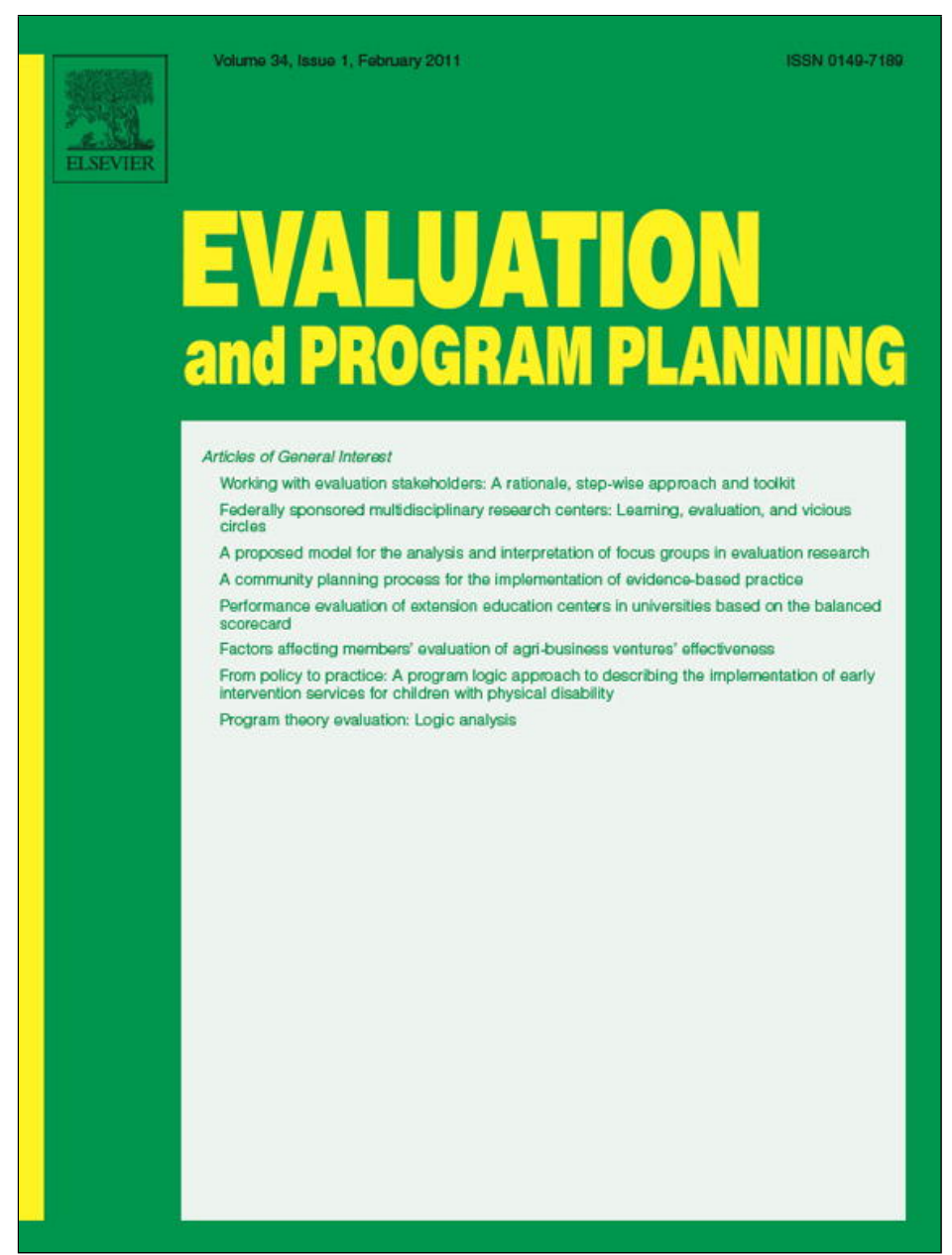

(This is a sample cover image for this issue. The actual cover is not yet available at this time.)

This article appeared in a journal published by Elsevier. The attached copy is furnished to the author for internal non-commercial research and education use, including for instruction at the authors institution and sharing with colleagues.

Other uses, including reproduction and distribution, or selling or licensing copies, or posting to personal, institutional or third party websites are prohibited.

In most cases authors are permitted to post their version of the article (e.g. in Word or Tex form) to their personal website or institutional repository. Authors requiring further information regarding Elsevier's archiving and manuscript policies are encouraged to visit:

http://www.elsevier.com/copyright 


\title{
Using GIS to enhance programs serving emancipated youth leaving foster care
}

\author{
Catherine J. Batsche ${ }^{\mathrm{a}, *}$, Steven Reader ${ }^{\mathrm{b}}$ \\ ${ }^{a}$ Department of Child and Family Studies, University of South Florida, United States \\ ${ }^{\mathrm{b}}$ Department of Geography, University of South Florida, United States
}

\section{A R T I C L E I N F O}

\section{Article history:}

Received 21 December 2010

Received in revised form 9 April 2011

Accepted 19 June 2011

\section{Keywords:}

Geographic Information Systems (GIS)

Foster care

Transition services

Child welfare

Youth programs

\begin{abstract}
A B S T R A C T
This article describes a GIS prototype designed to assist with the identification and evaluation of housing that is affordable, safe, and effective in supporting the educational goals and parental status of youth transitioning from foster care following emancipation. Spatial analysis was used to identify rental properties based on three inclusion criteria (affordability, proximity to public transportation, and proximity to grocery stores), three exclusion criteria (areas of high crime, prostitution, and sexual predator residence), and three suitability criteria (proximity to health care, mental health care, and youth serving organizations). The results were applied to four different scenarios to test the utility of the model. Of the 145 affordable rental properties, 27 met the criteria for safe and effective housing. Of these, 19 were located near bus routes with direct service to post-secondary education or vocational training programs. Only 6 were considered appropriate to meet the needs of youth who had children of their own. These outcomes highlight the complexities faced by youth when they attempt to find affordable and suitable housing following emancipation. The LEASE prototype demonstrates that spatial analysis can be a useful tool to assist with planning services for youth making the transition to independent living. (c) 2011 Elsevier Ltd. All rights reserved.
\end{abstract}

\section{Introduction}

Children are typically placed in foster care because they have experienced some form of maltreatment such as abuse, neglect, or abandonment. Although the goal of foster care is to re-unite children with their families, many youth remain in out-of-home care until they "age-out" of the foster care system and are legally emancipated, typically at age 18 . These youth become immediately responsible for all aspects of their daily living including housing, meal preparation, grocery shopping, transportation, education, employment, medical care, and other needed services.

Given the sudden transition from childhood dependency to adult self-sufficiency, it is not surprising that many foster youth experience housing problems following emancipation. Of the 30,000 youth who are emancipated from foster care in the United States each year (U.S. Department of Health and Human Services, 2009), an alarming number become homeless. Fowler, Toro, and Miles (2009) reported that approximately 20\% of former foster youth experienced chronic homelessness. Reilly (2003) found that $19 \%$ of the former foster youth lived on the streets and an additional $18 \%$ lived in a homeless shelter. Courtney, Dworsky, Lee,

\footnotetext{
* Corresponding author at: College of Behavioral \& Community Sciences, University of South Florida, MHC 1115, Tampa, FL 33612, United States. Tel.: +1 813974 7196; fax: +1 8139744699 .

E-mail addresses: cbatsche@bcs.usf.edu, cbatsche@usf.edu (C.J. Batsche).
}

and Raap (2010) reported that $37 \%$ of former foster youth had been homeless or had "couch surfed" by moving from one temporary housing arrangement with friends, family or strangers to another. Similar results have been reported in England where former foster youth constitute $8 \%$ of the homeless population (National Care Advisory Service, 2009). In a sample of 106 youth in England, 35\% reported they had experienced homelessness within the first 1215 months after leaving care (Wade \& Dixon, 2006).

Housing instability has been found to be related to emotional and behavioral problems, physical and sexual victimization, criminal conviction, and high school drop out status (Fowler et al., 2009). As such, housing instability can exacerbate the transitional process. Conversely, housing stability has been found to be the factor most closely associated with positive mental well-being in young people leaving foster care (Wade \& Dixon, 2006). Johnson et al. (2010) reported that high quality, well located, appropriate, and affordable housing enabled young people leaving care to build social networks and provided a base for them to engage with education, training, and employment opportunities. Therefore, it is essential that housing decisions incorporate multiple factors to support youth in transition (Torrico \& Bhat, 2009).

In recognition of the transitional problems experienced by foster youth in the United States (U.S.), Title IV-E of the Social Security Act was amended in 1986 to provide funds for states to create independent living programs. In 1999, the Foster Care Independence Act, specifically the John Chafee Foster Care Program, gave states the option to provide a broader array of 
services to youth, to extend Medicaid coverage through age 21, and to provide vouchers for education and training. Title IV-E was amended again in 2008 to extend the eligibility age for foster care maintenance payments for foster youth from 18 to 21 . In order to be eligible for these payments, foster youth had to be enrolled in a high school (or GED), post-secondary or vocational program; participate in a program designed to promote or remove barriers to employment; and be employed for at least $80 \mathrm{~h}$ per month.

As a result of these federal initiatives, many states in the U.S. have developed transition services to assist youth in identifying housing as part of independent living programs. These efforts are not limited to the United States. For example, in England, the National Care Advisory Service (2009) published a manual to support safe, suitable, and affordable housing options for youth leaving care. However, no systematic method has been identified to evaluate housing options that address the multiple needs and goals of youth leaving foster care. In order to address this gap in the service delivery system, we developed a model to assist transition case managers in their efforts to Locate and Evaluate Affordable, Safe, and Effective (LEASE) housing.

LEASE is a prototype that uses spatial analysis to map nine factors that are important in making affordable, safe, and suitable housing decisions with youth who are making the transition from foster care following emancipation. LEASE was developed using Geographic Information Systems (GIS), a tool that has the capability of combining multiple datasets and presenting the results on a map to provide new spatial perspectives to social problems (Joyce, 2009). The potential contributions of GIS have been promoted within child welfare for more than a decade. Robertson and Wier (1998) published an article describing how GIS could be used to enhance child welfare practice, program planning, and evaluation. Ernst (2000) and Freisthler, Levy, Gruenewald, and Chow (2006) used GIS to identify neighborhoods in which children may be at high risk for maltreatment. Leary (2009) incorporated GIS as part of a neighborhood analysis and confirmed that residential instability, impoverishment, and child care burden were positively associated with high foster care entry rates. No examples have been found in the literature that utilize GIS as a tool to address the complex problems faced by youth in transition. Thus, LEASE was designed to explore this possibility.

The geographic focus of the LEASE prototype was Hillsborough County, an area with a population of 1.2 million residents located on the west coast of Florida in the United States. Hillsborough County is the site for one of three national demonstration projects, Connected by 25 , that provide transition services to former foster youth between the ages of 18 and 25. Their mission is to ensure that foster care youth are educated, housed, employed and connected to a support system by age 25 .

\section{Methods}

\subsection{Spatial analysis overview}

GIS is a "computer system capable of capturing, storing, analyzing, and displaying geographically referenced information; that is, data identified according to location" (U.S. Geological Survey, 2007). Originally developed for the purpose of land-use mapping in Canada, GIS has come to be used for a wider range of applications including the study of human behaviors that can be measured by or are influenced by distance. In addition to using spatial data describing boundaries, locations, and other geographic dimensions, GIS has the capacity to incorporate a variety of data types such as census data, crime data, health care data, social services data, and other cultural and demographic data. These data are depicted as points, lines, or polygons on a map. The output of the spatial analysis can be converted to maps that depict the phenomenon being studied in a visual manner. In order to conduct spatial analysis, data must be available in a geocoded format or must be converted to $X, Y$ spatial references using a recognized geographic coordinate system.

Geocoded datasets were available from public sources for six of the nine factors included in LEASE. Data for the remaining three factors were geocoded by the authors using a national streets database (ESRI, 2008). The input datasets were imported into a geoprocessing model using ArcGIS 9.3 (ESRI, 2008). For each of the nine factors, geoprocessing operations were applied and an output dataset was generated.

\subsection{Inclusion criteria and analysis}

\subsubsection{Rationale for inclusion criteria}

Former foster youth have been found to be twice as likely as their same age peers to be unable to pay their rent (Courtney \& Dworsky, 2005). Typically, they do not have the resources to purchase or maintain a car and thus transportation becomes a barrier to work, education, health care, mental health care, social support, and routine activities of daily living such as grocery shopping (Courtney et al., 2007). Therefore, three criteria were used as a basis to include a rental property in the LEASE prototype: affordable housing, accessible transportation, and proximity to a grocery store.

\subsubsection{Inclusion criteria definitions}

Affordable Housing was defined as a multiple-unit, assisted rental property that provided rate adjustments for low-income individuals and families. The addresses of 2116 properties listed in the Assisted Rental Housing database (Florida Housing Clearinghouse, 2009) were imported into the GIS. This dataset contains fields denoting the physical address, longitude and latitude for each address, housing program type, and population served: family, persons with disabilities, elderly, and other categories. A rental property was included in LEASE if the address was in Hillsborough County and if the population served was "family (single or multiple resident)" or "persons with disabilities" (Criterion 1).

Public Transportation was defined as a bus route that provided service within the County. The Bus Transit Routes database (Florida Transit Information System, 2009) was imported to the GIS and the geocoded locations for all bus routes were transformed into lines on a map. All bus routes in the County were included in the model. A one-mile zone (buffer) was then created on either side of the mapped lines to define the geographic areas that were considered to be within reasonable walking distance to public transportation (Criterion 2).

Grocery Stores were defined as businesses listed as a supermarket in the Shopping Center database produced by the Florida Geographic Data Library (2005). The database was imported and the geocoded addresses for all supermarkets in the County were included in the analysis. These locations were buffered by a distance of one mile around the point of the supermarket address to produce the dataset for Criterion 3.

\subsubsection{Inclusion analysis data set}

Fig. 1 shows a map that presents the data for Inclusion Criteria 1,2 , and 3. Each triangle on the map represents a multiple-unit, assisted rental property in the County. The dark grey areas represent the one-mile buffers for bus routes and for grocery stores including areas where the two buffers overlap. Housing units that fell within the buffered areas were advanced to the next stage and were used to conduct the exclusion analysis. Housing units that fell outside the buffer zones were eliminated from the analysis. 


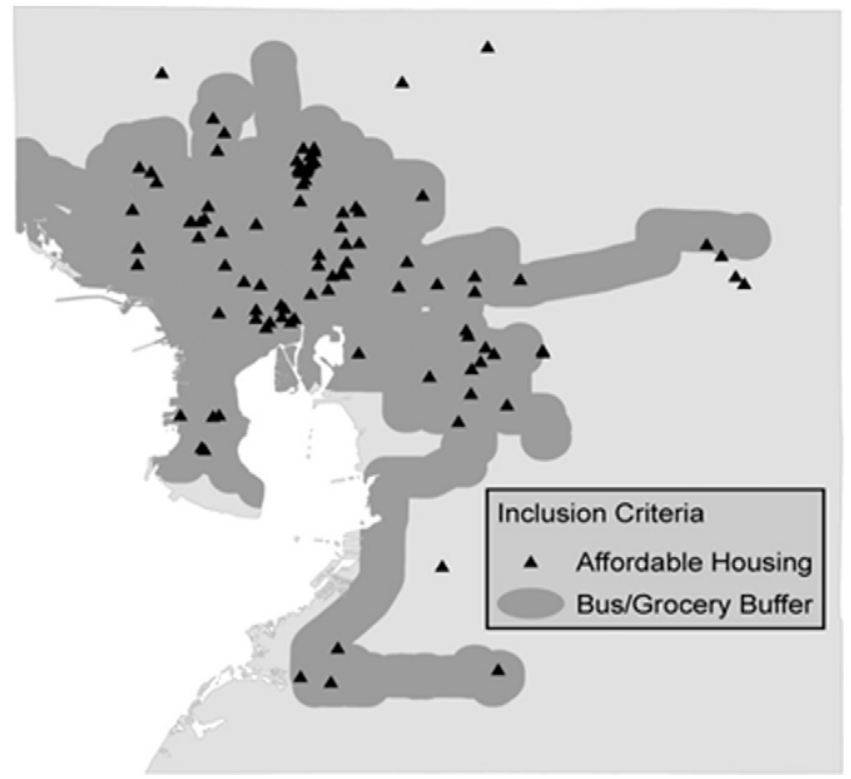

Fig. 1. Inclusion criteria: affordable housing units, bus route buffer, grocery store buffer.

\subsection{Exclusion criteria and analysis}

\subsubsection{Rationale for exclusion criteria}

Former foster youth have been found to have a high level of involvement in the criminal justice system (Courtney et al., 2010). As a result of poverty and homelessness, some have resorted to survival sex, the selling of sex to meet subsistence needs (Greene, Ennett, \& Ringwalt, 1999; Mendes \& Moslehuddin, 2006). Furthermore, Courtney and Heuring (2005) reported that $13 \%$ of female participants in their study of former foster youth had been sexually assaulted and/or raped within 12-18 months of discharge from care. While victimization can occur in any location, we opted to exclude geographic areas of high crime or prostitution as well as those that were in close proximity to the residence of a sexual predator.

\subsubsection{Exclusion criteria definitions}

A High Crime area was defined as a police grid with 200 or more offenses or arrests for murder/non-negligent manslaughter, forcible rape, robbery, aggravated assault, burglary, larceny/theft, motor vehicle theft, and arson (U.S. Department of Justice, Part I Crimes, 2008). These offenses are classified as major crimes involving violence or property and are required to be reported by local law enforcement agencies to the FBI. Crime data for LEASE were obtained from the County Sheriff's Office and the City Police Department and imported into the GIS. Police grids with more than 200 crimes in 2008 were selected from the crime database to produce the dataset for Criterion 4 and were displayed on the map as polygons.

An area of High Prostitution was defined as a police grid that had 20 or more arrests for the unlawful promotion of or participation in sexual activities for profit (U.S. Department of Justice, 2008). The data were obtained from the County Sheriff's Office and the City Police Department and imported into the GIS. Police grids with 20 or more prostitution arrests in 2008 were selected to produce the dataset for Criterion 5.

Sexual Predator was defined as an individual listed as a sexual predator on the Florida Department of Law Enforcement website (2009). State law prohibits sexual predators from living within 1000 feet of a school, day care center, park, playground, or other place where children regularly congregate. This standard was adopted for LEASE and the addresses for sexual predators were

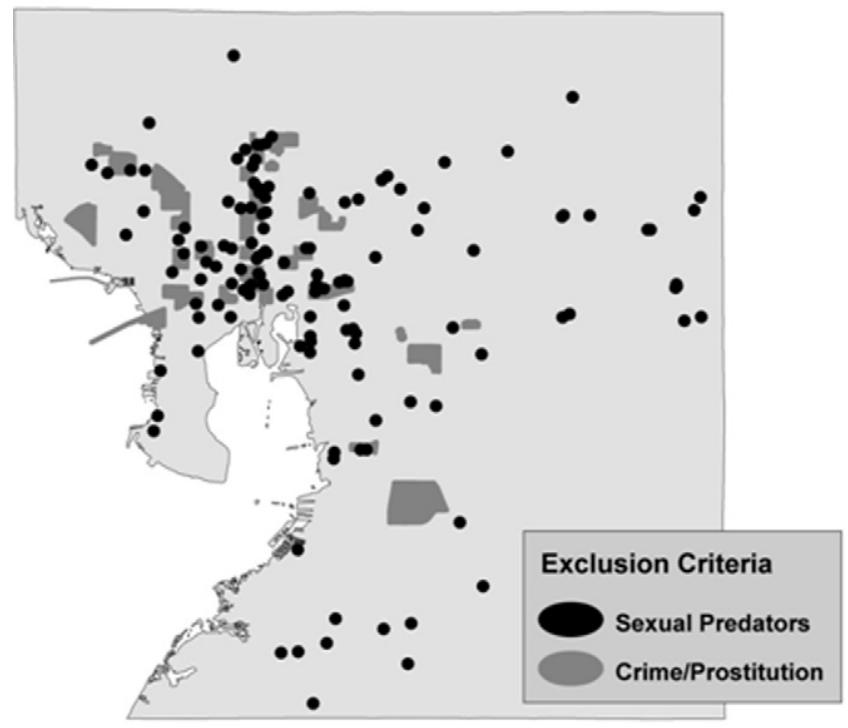

Fig. 2. Exclusion criteria: crime, prostitution, and sexual predator residence.

geocoded and imported into the GIS. The points of the mapped addresses were then buffered by a distance of 1000 feet to produce the dataset for Criterion 6 .

\subsubsection{Exclusion criteria data set}

Fig. 2 reflects the police grids designated as areas of high crime or prostitution (shown as polygons on the map) and the locations of the residences of sexual predators (shown as points). The data output for the exclusion analysis removed affordable housing units located in a police grid identified as having high incidences of crime or prostitution or located within the sexual predator buffer zone.

\subsection{Suitability criteria and analysis}

\subsubsection{Rationale for suitability criteria}

After the inclusion and exclusion analyses were completed, suitability modeling was conducted to classify a rental property based on its distance to selected services that support the needs of many foster youth. Rental properties that were closer to one or more of these service providers were considered to be more suitable than those that were further away from the service providers. While any number of suitability criteria can be included in the model, the rationale for those included in LEASE was based on service needs reported in the literature. For example, former foster youth are more likely than their non-foster care counterparts to describe their health as fair or poor (Courtney et al., 2007) with $30 \%$ experiencing a serious health problem after leaving foster care (Reilly, 2003). Likewise, former foster youth experience mental health problems at disproportionately higher rates than the general population (Courtney \& Heuring, 2005). These problems are exacerbated if youth lack access to support from friends, family, or social service organizations (Johnson et al., 2010; Simon, 2007). We therefore included suitability criteria that would increase the likelihood that a rental property would be in close proximity to health care, mental health care, and/or selected youth serving organizations that might provide ongoing social support.

Suitability modeling is a technique for applying a common scale of values to diverse and dissimilar inputs to create an integrated analysis. Suitability scores are calculated based on Euclidean Distance, i.e., the straight line distance between two points on a plane. In order to conduct this analysis, a map is converted to a grid-cell structure and the Euclidean Distance is calculated from the center of a source cell on the map (a cell with a potential 
housing unit) to the center of each surrounding cell. This analysis was conducted for each combination of cells on the County map. After the Euclidean Distance was calculated, properties were classified on a 10-point scale consisting of equal interval distances. A score of 10 was assigned to rental properties that were closest to a health service provider and a score of 1 was assigned to those that were furthest away from a health service provider. This process was conducted for each suitability criteria.

\subsubsection{Suitability criteria definitions}

Healthcare Providers were defined as walk-in clinics located in the County (Florida Department of Health, 2009). Addresses for walk-in clinics were selected from the Florida Healthcare Facilities database, the Euclidean Distance was calculated in GIS, and the outcome was classified on the 10-point suitability scale (Criterion 7).

Mental Health Providers were defined as counselors, social workers, or child and adolescent guidance counselors listed in the Florida Division of Emergency Management database (2008). Addresses for mental health providers in the County were selected, the Euclidean Distance was calculated, and the outcome was classified on the10-point suitability scale (Criterion 8).

Youth Serving Organizations were defined as agencies that provide social activities or social services to youth over the age of 18. Addresses for youth serving organizations were obtained from the Community \& Fraternal Centers database (Florida Geographic Data Library, 2008) and supplemented with data for selected local community organizations that provide support services for young adults. The Euclidean Distance was calculated and the outcome was classified on the10-point suitability scale (Criterion 9).

For purposes of the prototype, suitability scores were weighted as follows: Healthcare (.20), Mental Health (.20), and Youth Serving Organization (.60). The weighted sum resulted in values ranging from 0 to 9.8 on the 10 -point suitability scale. A rental property was considered suitable if it had a score that was greater than or equal to 4.0 (refer to Section 5 of this paper for additional information on weighting). The resulting analysis was used to produce a map of rental properties that reflected the weighted suitability criteria as well as the inclusion and exclusion criteria.

\section{Results}

\subsection{Inclusion results}

The results of the LEASE analyses are presented in Table 1. Of the 2116 assisted rental properties in the state, 145 were located in the County and 109 were designated for families (single or multiple resident) or for persons with disabilities. When the 46 County bus routes were buffered and combined with 184 buffered grocery store address points, 102 rental properties met the inclusion criteria.

Table 1

Results of inclusion, exclusion, and suitability analyses and scenario testing.

\begin{tabular}{lc}
\hline Analysis phase & Properties (N) \\
\hline Inclusion analysis: State & 2116 \\
Inclusion analysis: County & 145 \\
Inclusion analysis: accessible transportation & 109 \\
Inclusion analysis: accessible grocery store & 102 \\
Exclusion analysis: high crime & 83 \\
Exclusion analysis: prostitution & 81 \\
Exclusion analysis: sexual predator & 78 \\
Suitability analysis: health, mental health, youth services & 27 \\
Scenario One: high school youth/no children & 27 \\
Scenario Two: post-secondary youth/no children & 19 \\
Scenario Three: high school youth with children & 6 \\
Scenario Four: post-secondary youth with children & 6 \\
\hline
\end{tabular}

\subsection{Exclusion results}

The results of the exclusion analysis identified 30 high-crime police grids in the County (range of 200-791 crimes per grid). When rental properties located in these 30 areas were eliminated from the results of the inclusion analysis, 83 of the 102 properties remained. The exclusion analysis identified 21 police grids with active areas of prostitution (range of 20-45 arrests per grid). After rental properties located in these grids were removed, only two additional properties were eliminated because most of the areas of high prostitution coincided with areas of high crime. When the sexual predator criterion was applied, the number of rental properties was reduced from 81 to 78 . Once again, many of the sexual predator addresses were located in areas of high crime and high prostitution so only three additional properties were eliminated. These 78 properties were advanced to the suitability analysis.

\subsection{Suitability analysis}

The suitability analysis was based on the proximity of a rental property to selected categories of service providers. The initial step of the analysis identified 46 walk-in clinics in the County, 99 mental health care providers, and 25 youth-serving organizations. After the weighted sum was applied, only 27 of the 78 rental properties had suitability scores of 4.0 or higher. These 27 rental properties represented the final output for the LEASE prototype.

\section{Testing the LEASE prototype}

\subsection{Test scenarios}

The LEASE prototype was designed to identify housing that not only was affordable, safe, and accessible but also was located in areas that support the educational goals and parental status of youth. Four scenarios were selected to test the ability of the model for youth with differing needs: (1) youth in high school with no children; (2) youth in a post-secondary program with no children; (3) youth in high school with children of their own; and (4) youth in a post-secondary program with children of their own. The four scenarios addressed only foster youth attending school because the focus of LEASE was on youth who met state eligibility criteria for transition services following emancipation. Transition services included a monthly stipend roughly equivalent to minimum wage. In order to be eligible for the stipend, youth had to be attending a high school, GED, vocational/technical program, community college or university and had to be making continuous progress toward their educational goals.

\subsection{Scenario data sets}

Two additional data sets were needed to apply the model to the four scenarios. First, a data set was developed containing bus routes that provided direct service to a public community college, university, or vocational-technical training program. For purposes of prototype development, direct bus routes were considered preferable to transfer routes to reduce travel time to educational programs. Second, a data set of child development programs was added to support positive parenting for youth with children of their own: Parent Education, Nutrition Education, and Early Childhood Education. The original plan for LEASE was to include the locations of all child care programs as part of the model. However, a large number of subsidized child care programs existed in the areas surrounding the 27 properties and their inclusion provided no additional discrimination in housing alternatives. Therefore, only child development programs were selected to test the model. 
Post-Secondary Bus Routes were obtained from the County system map. Route number(s) that provided direct bus service to each of the three public vocational schools were selected from the Florida Transit Information System (2009) database and buffered by one mile. This procedure was repeated for bus routes providing direct service to each of the five public community college and university campuses in the County. The three resulting datasets were combined with the output of the suitability analysis for application to Scenarios Two and Four (youth attending postsecondary programs, with or without children of their own).

Parent Education programs were defined as the service centers operated by Baby Bungalow, an early childhood resource program that provides services in five County locations for parents of children from birth to age five (Child Abuse Council of Hillsborough County, 2009). Nutrition Education was defined as the locations of eight Women, Infant, and Children's (WIC) programs in the County that provide nutrition education for pregnant mothers, new mothers, and children up to the age of five who meet income requirements (Hillsborough County Health Department, 2009a, 2009b). Early Childhood Education was defined as the 19 Head Start centers. These programs promote school readiness of young children by providing educational, health, nutritional, social and other services to children and families (Hillsborough County Health Department, 2009a, 2009b). Addresses for these sites were obtained from agency websites, geocoded to the street address level, and imported to the GIS. The address points were buffered by .50 mile as were the lines representing bus routes that provided service to these sites. In contrast to the one-mile buffer used in the inclusion analysis, a smaller buffer (.50 miles) was applied in recognition of the challenge of commuting with young children. The results were combined with the outcomes of the suitability analysis to provide the data for Scenarios Three and Four (youth attending high school or a post-secondary program who have children of their own).

\subsection{Results of prototype testing}

Scenario One was developed to identify affordable housing for foster youth who were in high school at the time of emancipation and who had no children of their own. As long as these youth were still attending high school, they were eligible for bus transportation provided by the school district regardless of where they lived. Therefore, these youth had no additional transportation needs for educational purposes other than those already identified in the LEASE inclusion criteria. As a result, all 27 rental properties were considered to be geographically appropriate for youth in Scenario One (Fig. 3).

Scenario Two was developed for youth who were pursuing post-secondary education and who had no children of their own. Of the 27 rental properties identified through LEASE, 19 were located within one mile of a bus route serving one or more postsecondary options. Fig. 4 depicts the locations of the 19 rental properties with direct bus service to a public university (black lines), vocational school (dark gray lines), or community college campus (white lines).

Scenario Three targeted youth who were attending high school and who were parents of young children. As in Scenario One, bus service to the high school was provided by the school district so no special transportation was needed for school attendance. However, these youth needed public transportation to access the child development programs. Only six $(n=6)$ rental units were located within .5 mile of a bus route that provided direct service to the child development programs and also met the criteria for affordability, safety, and suitability (Fig. 5).

Scenario Four was designed for youth who were parents of young children and who were attending a post-secondary

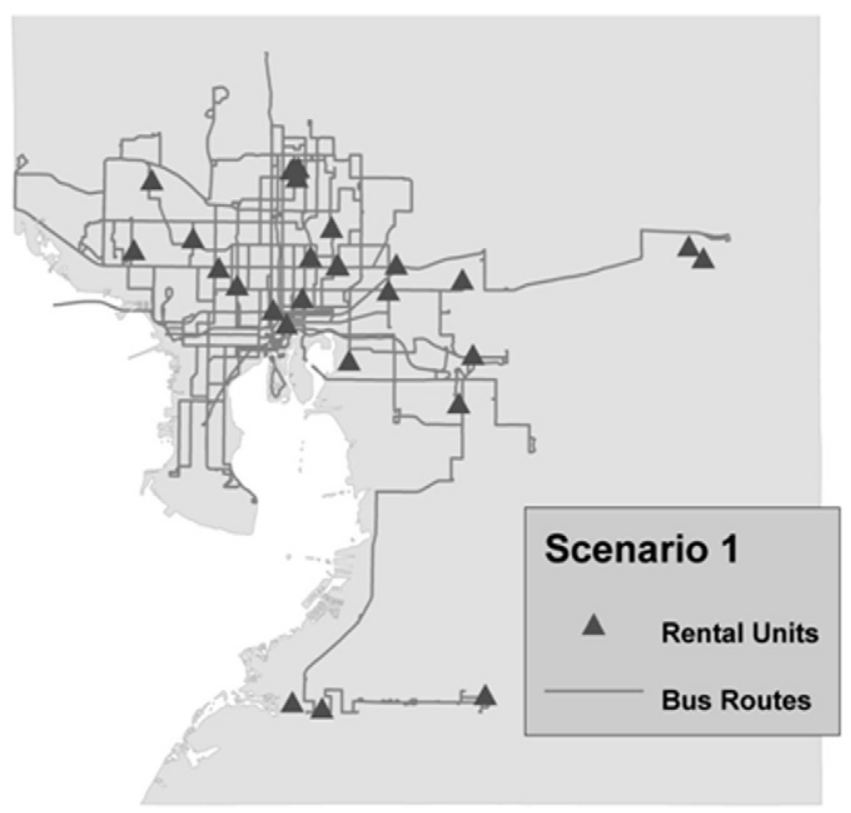

Fig. 3. Affordable housing units for youth in Scenario One (high school-no children).

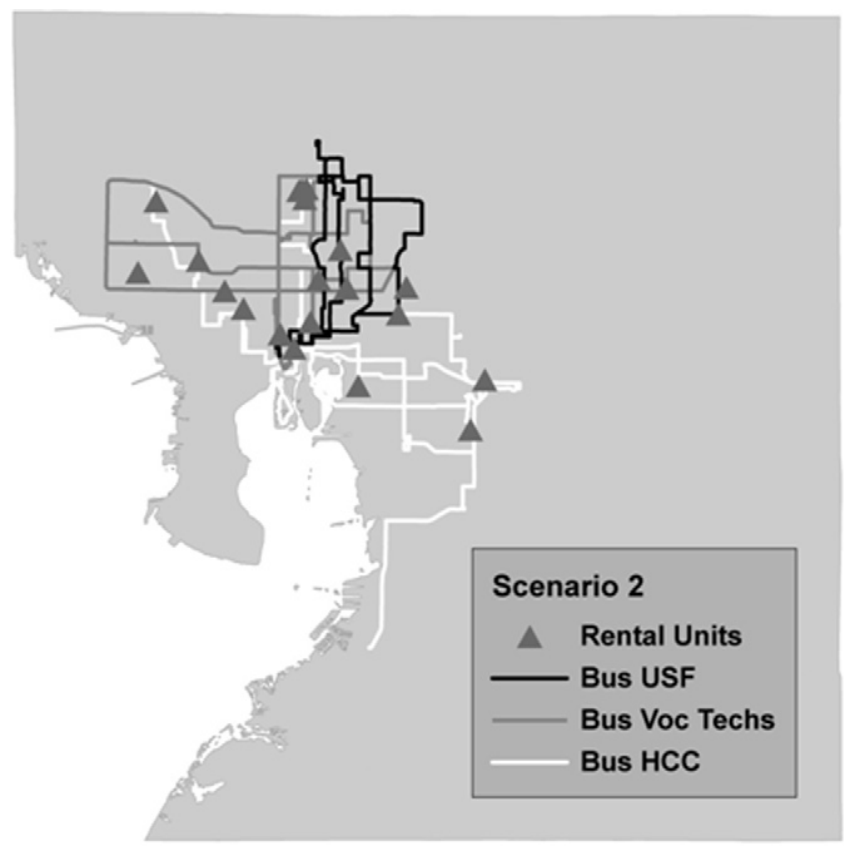

Fig. 4. Affordable housing units for youth in Scenario Two (post-secondary-no children).

institution. These youth not only required bus service to child development programs but also needed bus service to one of the post-secondary options. The outcome for Scenario Four produced identical outcomes as Scenario Three with only six rental properties meeting all of the conditions (Fig. 5).

\section{Discussion}

\subsection{The LEASE prototype}

This paper described a prototype that was developed to explore the potential of using GIS to locate and evaluate affordable, safe, and effective housing for youth leaving foster care following 


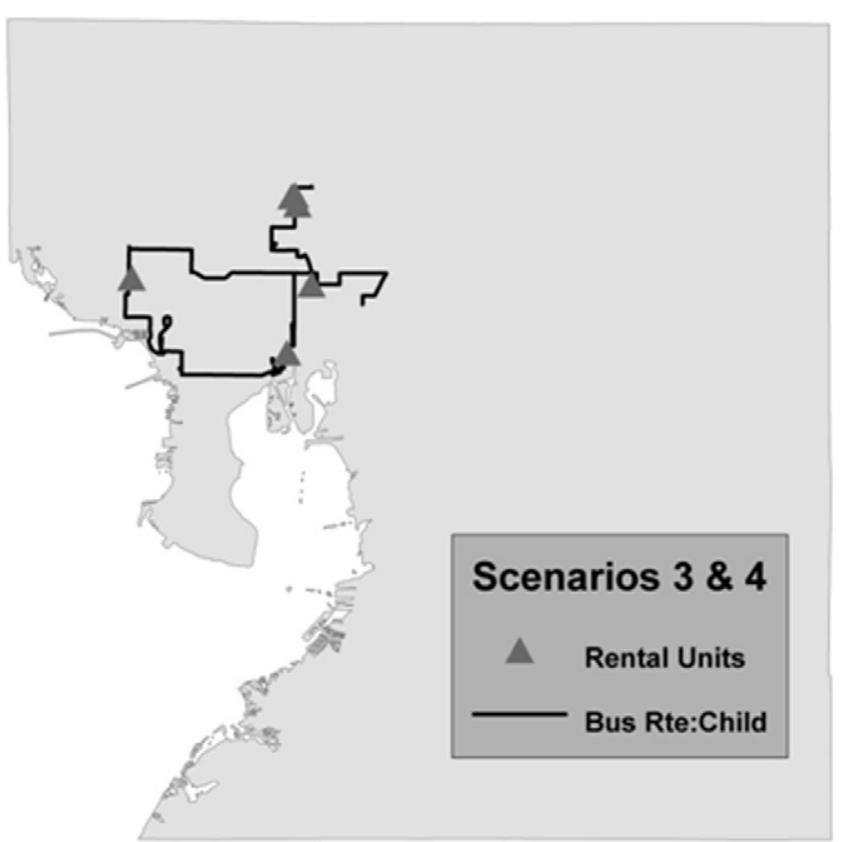

Fig. 5. Affordable housing units for youth in Scenarios Three and Four (high school or post-secondary school-with children).

emancipation. Only 27 of the 145 assisted rental properties in the County met the LEASE criteria for safe and effective housing. These results were further reduced when transportation to postsecondary education programs and child development services were included. Given that an average of 125 youth in Hillsborough County age out of foster care each year, the small number of rental properties that met the LEASE criteria highlights the challenges these youth face in finding suitable housing. Even if the youth can find housing that is affordable, the outcomes of the prototype suggest that youth have limited choices of housing that is in a relatively safe neighborhood, provides access to public transportation and other needed services, and supports their educational goals and parental responsibilities.

The spatial analyses conducted in the LEASE prototype demonstrated that GIS can be useful when planning services for youth making the transition to independent living. Large data sets were combined and integrated into maps that portrayed the information in a simple visual presentation. These maps can be used to facilitate dialogue with youth as they consider their housing options. Foster care leavers are not an homogenous group however and they have a diverse set of needs and aspirations that should be considered when identifying housing options. Ideally, youth should have a voice in housing decisions, and to the extent possible, should be offered a choice of housing that will meet their needs (National Care Advisory Service, 2009). Spatial analysis can be used to facilitate these choices. For example, the LEASE prototype identified six apartment complexes that provided service accessibility for youth with children. These six options could be discussed with youth who have children of their own so they can prioritize the choices available to them and understand the implications of each option on other aspects of their life (National Care Advisory Service, 2009). Narrowing the housing options through LEASE provides a structure for youth and transition case managers to make strategic choices about where youth will live.

LEASE can also be used at the community level as a tool to explore alternative housing options for youth leaving care. Child welfare agencies and local housing authorities can use GIS to examine ways to identify the shortage of housing that is safe, affordable, and effective in meeting the needs of youth and then work together to develop plans to address housing needs. This could take the form of local agreements with housing authorities to designate a specific number of apartments in the most "suitable" complexes based on criteria developed by the local child welfare agency. Similarly, the data and maps could be used to plan future housing and transportation hubs that would co-locate affordable housing with critical service providers such as schools, medical facilities, mental health providers, youth serving organizations, and other important services.

\subsection{The LEASE criteria}

LEASE was developed to illustrate the capability of GIS to assist program planners who are working with youth in transition. Only a small number of criteria were included for prototype development. The factors in LEASE were not intended to represent a definitive set of criteria for selecting housing but rather to serve as examples of the capability of GIS. Even though these criteria were only examples, additional discussion about the limitations of some of the criteria is warranted in the event they will be used by local planners.

Affordable housing was defined as an assisted rental unit purchased or constructed with federal, state, or local funds that require rental rate adjustments based on income of the resident. Even though these apartment complexes provide reduced rates for low-income individuals and families, they are not necessarily affordable for youth leaving foster care. Therefore, program planners should supplement the assisted rental housing dataset with locally developed lists of rooming houses and other affordable options in order to produce a viable set of housing alternatives for youth.

Accessibility to public transportation was included in LEASE because most youth leaving foster care do not own cars at the time of emancipation. For purposes of the prototype, a one-mile buffer was selected as the maximum distance a rental property could be from a bus stop. A smaller buffer, such as .5 mile, may be a more realistic distance to accommodate youth preferences for walking. However, when a .5 mile buffer was applied in LEASE, all rental properties in non-urban settings were eliminated. In order to continue to test the model for youth in non-urban as well as urban areas, the buffer distance was changed to one mile. An alternative strategy would have been to use different criteria for different geographic areas such as a .50 mile buffer for apartment complexes in urban areas where multiple bus routes existed and a 1.0 mile buffer for apartment complexes in rural communities where there were fewer bus routes. The size of the buffer is at the discretion of the developer and can be adjusted to reflect each community.

Another factor to consider in making decisions about bus routes or other forms of public transportation is to determine if it is more effective to include only routes that have direct service to a destination or if is acceptable to include routes that require one or more transfers to reach a destination. We included only bus routes with direct service to educational institutions and/or child development services. This decision was based on the experience of local transition case managers who reported that youth often experienced travel delays and frustrations when having to transfer from one bus to another. If the transfer connection was not on time, the youth would be late to class or even decide not to attend class rather than walk in late. Therefore only bus routes requiring no transfers were included. If transfer routes had been included in the prototype, the number of housing options would have increased, particularly for youth who had children of their own. However, the logistical challenges involved in commuting with children persuaded us to include only direct bus routes for purposes of prototype development. If, in practice, the number of rental properties proved too small using only direct bus routes, transfer 
routes could be added. These options could then be discussed with the youth to explore the trade-offs that would be made by selecting a residence that provided transfer service to priority destinations rather than one that had direct service.

The exclusion criteria were intended to eliminate rental properties in areas of high crime, prostitution, and proximity to sexual predators. Exclusion of these localities obviously does not guarantee a safe or crime-free living environment. However, criteria such as these can be included in local models to reduce the probability of exposure to environments that place youth at risk. The LEASE prototype utilized the number of crimes in a neighborhood rather than the rate of crime. Local developers may want to adjust the crime data based on the number of residents in each police grid to produce crime rates adjusted for the size of the population. Crime rates were not used in the prototype development because of complexities associated with obtaining current population data for all police grids (the analysis was conducted near the end of the census decade and comparable, current data were not available for all police grids). The use of crime rate data, as opposed to number of crimes, might provide a different set of high crime neighborhoods than those used in the prototype. This may not be the case for prostitution data however. The number of arrests for prostitution most likely under-represents actuality given the challenges faced by law enforcement in policing prostitution activity, such as street prostitution which is more easily detected than indoor prostitution (Center for Problem Oriented Policing, 2010). Rather than relying on arrest data, it might make more sense to interview police officers who patrol the streets and ask them to identify geographic areas with high prostitution activity or to interview or survey those working in prostitution (see discussion in the draft article by Levitt \& Venkatesh, 2008). These areas could then be mapped to provide a more accurate view of high activity areas for prostitution.

The utilization of sexual predator residence was a unique addition to the LEASE model. Florida Statutes (2010) prohibit sexual predators whose victim was under the age of 18 from living within 1000 feet of a school, day care center, park, playground, or other place where children regularly congregate. This prohibition did not technically apply to the LEASE target population, who were all 18 years or older. However, the 1000 foot buffer was adopted as a standard for two reasons. First, some youth who are emancipated from foster care have children of their own making distance from sexual predators more relevant. Second, it was assumed that transition case managers would want to avoid co-location of a foster youth in a rental property that also housed a sexual predator. Sexual predators lived in a variety of locations across the County and many lived in or were in close proximity to affordable rental properties. Regardless of whether LEASE is adopted as a model for transition housing services, local agencies should consider incorporating distance from sexual predator residences as one of the factors in identifying housing options for youth.

In addition to the inclusion and exclusion criteria, three weighted suitability criteria were used in the model: proximity to health care, mental health services, and youth serving organizations. The weights assigned to these services can be set at any value based on the needs of the youth and availability of services in the community. In this case, a higher weight (.60) was assigned to youth serving organizations because these entities provide a daily source for social interaction and informal support, a factor that has previously been found to be critical to successful transition (Simon, 2007). Consistent and reliable sources of social support are important so that youth have access to services when they need information or help if problems emerge with housing and other areas of their lives (Johnson et al., 2009). In contrast to the ongoing need for social support, health services and mental health services may only be needed on an occasional basis by many youth. Therefore, lower weights (.20) were assigned to each of these services. On the other hand, if LEASE was being used to identify housing for a youth with significant health or mental health needs, higher weights could be assigned to these services or they should be added as an inclusion criteria.

A minimum suitability score of 4.0 (on a scale of 1-10) was required in order for a rental property to continue to be included in the LEASE model. The cut-off score can be set at any level based on the judgment of program planners and needs of the population being served. For purposes of prototype development, a minimum score of four was selected because it would guarantee that youth had access to at least one youth serving organization (previously weighted at .60 ) or two other services (weighted at .20 each) that would support their transition. If the suitability score had been set higher than 4.0 in the prototype, all properties that were not within close proximity to a youthserving organization would have been eliminated because of the higher weighting assigned to these services. While a score of 4.0 was satisfactory for the prototype, it may not reflect local needs. Thus, these weights can be adjusted by users to reflect local preference or individual client needs.

\subsection{Lessons learned}

The development of the LEASE prototype supported the findings of Joyce (2009) regarding the positive contributions of GIS to decision-making processes. First, LEASE demonstrated the power of GIS to integrate and analyze large amounts of data related to factors associated with the housing needs of emancipated foster youth. Transition case managers routinely consider many of the LEASE factors when identifying housing for youth leaving foster care. However, they have not had a systematic method to manage data associated with these factors that produces results within the context of geographic place. GIS provides a tool to support informed decision making. Second, the data output for LEASE were presented in a visual format that is often easier to understand than multiple data tables. Maps can facilitate the decision-making dialogue with youth by showing them the location of housing options in relation to needed services. Third, LEASE demonstrated the potential that GIS has to add to the existing repertoire of tools used in program planning and decision making for those working with youth transitioning from foster care.

At a broader level, the development of LEASE demonstrated the importance of using a cross-disciplinary team when including spatial analysis in program planning. In England, the National Care Advisory Service (2009) stated that local authorities should work together to ensure that housing staff and youth service providers have the skills to map housing options as well as support service needs for youth leaving care. These collaborations will be enhanced by the use of cross-disciplinary teams. When developing LEASE, a human service professional collaborated with a geography professional to design the model. The human services professional (who had obtained only a basic understanding of GIS by taking a introductory university course) collected information about the criteria from a local agency that wanted to enhance its program planning and service delivery for youth in transition. The geographer then guided the human services professional in the development of a GIS model that reflected programmatic needs. Joyce (2009, p. 840) reported that the "use of GIS in collaborative contexts is not merely a noble and worthwhile pursuit, it is an essential one given the possibilities for misuse of GIS technologies or misunderstanding of GIS outputs." Without knowing the basics of GIS, it may be difficult for program planners in human service fields to conceptualize problems that lend themselves to spatial 
analysis or to fully utilize the array of analytical functions that GIS offers. Likewise, without understanding the policies and procedures of human service programs, it would be difficult for GIS experts to identify meaningful applications to social problems or to interpret the outcomes appropriately. By working in cross-disciplinary teams, the expertise of both professions can increase the credibility and validity of the spatial analysis application.

Most importantly, the prototype demonstrated the capacity of GIS to modify the outcomes based on different scenarios of interest to program planners and evaluators. For example, if accessibility to a specific service such as a drug treatment program is critical, a new data layer can be added to the model. A user-friendly web interface can be developed for GIS applications to allow maps to be customized to answer specific questions (see the Hillsborough Community Atlas (2010) for an example of interactive mapping). Data layers can be turned on or off to produce new displays depending on their importance in a particular case. Thus bus routes to particular job sites, recreational facilities, probation officer offices, substance abuse agencies, Medicaid providers, or other needed services can be added as data layers and toggled on or off to produce the appropriate combination. The major lesson learned in developing the LEASE prototype was that GIS is a dynamic, interactive tool that allows users to incorporate numerous human services factors as long as data can be associated with geographic parameters.

\section{Conclusion}

LEASE provides an example of the potential of using GIS as a tool to enhance program planning for the delivery of human services. The model itself will not solve the complex housing and transitional problems faced by youth who exit the foster care system. However, LEASE provides a strategic method to inform decision making related to housing alternatives for youth making the transition from foster care to independent living. At the individual level, the maps produced through spatial analysis should be used to engage youth in a discussion of housing alternatives and the advantages and disadvantages of each possibility. At the organizational level, transition specialists and local housing authorities should use spatial analysis to plan for the expansion of affordable housing units in areas that are colocated with services needed by youth. At the policy level, cross disciplinary training and collaboration should be required to expand the use of spatial analysis in program planning, delivery, and evaluation. Policy makers should also support research to test the impact of spatial analysis models on improving transition outcomes and to assess the effectiveness of these models with different combinations of factors and criteria.

The National Care Advisory Service (2009) in England recommended that service providers and housing departments should work together to regularly map housing and support services available in their areas. A similar policy should be adopted in the United States. The LEASE prototype demonstrated that GIS can be an effective tool for these collaborations. Because the choice of housing has a significant impact on the transition trajectory, it is imperative that housing decisions be informed by data that will promote housing stability by providing affordable, safe, and effective alternatives for youth following emancipation from foster care.

\section{References}

Center for Problem Oriented Policing. (2010). Responses to the problem of street prostitution. Retrieved from http://www.popcenter.org/problems/street_ prostitution/3

Child Abuse Council of Hillsborough County. (2009). Baby Bungalow program. Retrieved from http://www.child-abuse-council.org/programs.html
Courtney, M. E., \& Dworsky, A. (2005). Midwest evaluation of adult functioning of former foster youth: Outcomes at age 19. University of Chicago: Chapin Hall. Retrieved from http://www.chapinhall.org/research.

Courtney, M. E., \& Heuring, D. H. (2005). The transition to adulthood of for youth "aging out" of the foster care system. In D. W. Osgood, E. M. Foster, C. Flanagan, \& G. R Ruth (Eds.), On your own without a net: The transition to adulthood for vulnerable populations. John D and Catherine T MacArthur Foundation.

Courtney, M. E., Dworsky, A., Cusick, G. R., Havlicek, J., Perez, A., \& Keller, T. (2007). Midwest evaluation of the adult functioning of former foster youth from Wisconsin: Outcomes at age 21. University of Chicago: Chapin Hall. Retrieved from http:// www.chapinhall.org/research.

Courtney, M. E., Dworsky, A., Lee, J. S., \& Raap, M. (2010). Midwest evaluation of adult function of former foster youth: Outcomes at ages 23 and 24. University of Chicago: Chapin Hall. Retrieved from http://www.chapinhall.org/research.

Ernst, J. S. (2000). Mapping child maltreatment: Looking at neighborhoods in a suburban county. Child Welfare, 79, 555-572.

ESRI. (2008). Environmental Systems Research Institute. ArcGIS 9.3. Redlands, CA.

Florida Department of Health. (2009). Medical clinics. Retrieved from http:// www.fgdl.org/metadataexplorer/explorer.jsp

Florida Department of Law Enforcement. (2009). Florida sexual predator registry. Retrieved from http://offender.fdle.state.fl.us/offender/homepage.do

Florida Division of Emergency Management. (2008). Retrieved from http://www.floridadisaster.org/gis/index.asp

Florida Geographic Data Library. (2008). Community and fraternal centers. Retrieved from http://www.fgdl.org/

Florida Geographic Data Library. (2005). Super markets. Retrieved from http:// www.fgdl.org/metadataexplorer/explorer.jsp

Florida Housing Data Clearinghouse. (2009). Assisted rental housing units. Retrieved from http://flhousingdata.shimberg.ufl.edu/

Florida Statutes. (2010). 775.21 Florida Sexual Predators Act. Retrieved from http:// www.flsenate.gov/

Florida Transit Information System. (2009). Bus transit routes. Retrieved from http:// www.ftis.org/ftgis.html

Fowler, P. J., Toro, P. A., \& Miles, B. W. (2009). Pathways to and from homelessness and associated psychosocial outcomes among adolescents leaving the foster care system. American Journal of Public Health, 99, 1453-1458doi:10.2105/AJPH.2008. 142547.

Freisthler, B., Levy, F., Gruenewald, P. J., \& Chow, J. (2006). Methods and challenges of analyzing spatial data for social work problems: The case of examining child maltreatment geographically. Social Work Research, 30, 198-210.

Greene, J. M., Ennett, S. T., \& Ringwalt, C. L. (1999). Prevalence and correlates of survival sex among runaway and homeless youth. American Journal of Public Health, 89, 1406-1409 Retrieved from http://www.ncbi.nlm.nih.gov/pmc/articles/ PMC1508758/pdf/amjph00009-0102.pdf.

Hillsborough Community Atlas. (2010). Interactive mapping. Retrieved from http:// www.hillsborough.communityatlas.usf.edu/help/about.asp

Hillsborough County Health Department. (2009a). Head Start programs. Retrieved from http://www.hillsboroughcounty.org/headstart/

Hillsborough County Health Department. (2009b). Women, Infant, Children (WIC) program. Retrieved from http://www.hillscountyhealth.org/wic/wic_main.htm

Johnson, G., Natalier, K., Mendes, P., Liddiard, M., Thoresen, S., Hollows, A., et al. (2010). Pathways from out-of-home care. Australian Housing and Urban Research Institute, Issue 131. Retrieved from: http://www.ahuri.edu.au/publications/projects/p30540.

Joyce, K. (2009). "To me, it's just another tool to help understand the evidence": Public health decision-makers' perceptions of the value of geographical information systems (GIS). Health and Place, 15, 831-840doi:10.1016/j.healthplace.2009.01.004.

Leary, B. (2009). Neighborhood structure and foster care entry risk: The role of spatial scale in defining neighborhoods. Children and Youth Services Review, 31, 331337doi:10.1016/j.childyouth.2008.08.001.

Levitt, S. D., \& Venkatesh, S. A. (2008). An empirical analysis of street-level prostitution: Draft report. Retrieved from http://www.international.ucla.edu/article.asp?parentid $=85677$

National Care Advisory Service. (2009). Journeys to home: Care leavers' successful transition to independent accommodation. London: National Care Advisory Service. Retrieved from http://www.leavingcare.org/?page_ID=113

Mendes, P., \& Moslehuddin, B. (2006). From dependence to interdependence: Towards better outcomes for young people leaving state care. Child Abuse Review, 15, 110126doi:10.1002/car.932.

Reilly, T. (2003). Transition from care: Status and outcomes of youth who age out of foster care. Child Welfare, 82, 727-746 0009-4021/2003/060727-20.

Robertson, J. G., \& Wier, K. R. (1998). Using geographical information systems to enhance community-based child welfare services. Child Maltreatment, 3, $224-$ 234doi: $10.1177 / 1077559598003003002$.

Simon, A. (2007). Early access and use of housing: Care leavers and other young people in difficulty. Child and Family Social Work, 13, 91-100doi:10.1111/j.1365-2206. 2007.00524.x.

Torrico, R., \& Bhat, S. (2009). Connected by 25: Financing housing supports for youth transitioning out of foster care. Washington, DC: The Finance Project. Retrieved from http://www.financeproject.org/index.cfm?page=32

U.S. Department of Health and Human Services. (2009). Adoption and Foster Care Analysis and Reporting System (AFCARS). Retrieved from http://www.acf.hhs.gov/ programs/cb/systems/afcars/about.htm

U.S. Department of Justice, Federal Bureau of Investigation. (2008). Uniform Crime Report. Retrieved from http://www.fbi.gov/stats-services/publications 
U. S. Geological Survey. (2007). Geographic Information Systems. Retrieved from http://egsc.usgs.gov/isb/pubs/gis_poster/index.html

Wade, J., \& Dixon, J. (2006). Making a home, finding a job: Investigating early housing and employment outcomes for young people leaving care. Child and Family Social Work, 11, 199-208doi:10.1111/j.1365-2206.2006.00428.x.

Catherine Batsche, Ph.D. is Interim Dean of the College of Behavioral \& Community Sciences at the University of South Florida. She is a school psychologist whose recent work has been conducted with youth in the foster care system, particularly those with mental health and other behavioral disorders.

Steven Reader, Ph.D. is an Associate Professor of Geography in the College of Arts \& Sciences at the University of South Florida. He teaches courses in Geographic information Systems and conducts research grant reviews with the National Institutes of Health on projects incorporating GIS as part of the research methodologies. 